\title{
Testimonio y subalternidad hoy. \\ En torno a dos colectivos de mujeres mexicanas en lucha
}

Testimony and Subalternity today. About the struggle of two Mexican women collectives

\section{MARIANA ESPELETA}

\section{ITESO UNIVERSIDAD JESUITA DE GUADALAJARA marianae@iteso.mx}

Profesora en Iteso, ha realizado una tesis doctoral en la Universidad de Barcelona con el título Subalternidades femeninas: la autorrepresentación como resistencia. Ha publicado diversos artículos sobre la obra de Antonio Gramsci y sobre colectivos de mujeres en América Latina.

Resumen: El artículo explora las nociones gramscianas de Hegemonía y Subalternidad y analiza el lugar que el testimonio puede tener en relación con ellas. Desde ese entramado teórico, se sirve de dos ejemplos de colectivos de mujeres actuales en Mexico para dar cuenta de las potencialiades de la autorrepresentación como herramienta de resistencia en un contexto de subalternización.

Palabras claves: Hegemonía, subalternidad, Patronas, Ciudad Juárez.

\begin{abstract}
The paper focuses in the gramscian notions of Hegemony and Subalternity and analyzes the place of witnessing within them. From this theoretical issue, the author studies two cases of women's organization and the potentialities of autorrepresentation as a cultural tool for struggling.
\end{abstract}

Palabras claves: Hegemony, Subalternity, Patronas, Ciudad Juárez. 
Mariana Espeleta. Testimonio y subalternidad hoy...

La otra dificultad que siempre tenemos las compañeras es con las diferentes lenguas que se hablan en la zona. A veces hay compañeras que dicen que no le entienden cuando no es su lengua, pero siempre a través de otra compañera le tienen que traducir lo que se está diciendo. Eso es lo que se hace, buscarle quién le va a traducir, porque eso es lo que a veces dicen, que no le entienden al castilla, pero se busca quién se lo traduzca. Así es como estamos viviendo las dificultades en nuestra zona (FZLN, 2013: 12)1.

Escribo este artículo lejos de la crítica literaria y los estudios culturales, pero cerca de algunos de los sujetos que comúnmente son concebidos como subalternos, y privilegiados para contar "la historia desde abajo". Comienzo estableciendo dicha posición porque se relaciona estrechamente con el propósito del artículo, que consiste primeramente en reflexionar una vez más sobre la relación entre el testimonio y el subalterno, pero explorando de manera crítica el concepto demasiado sobrentendido de "subalternidad", buscando relacionarlo con un marco político más amplio, siguiendo las ideas de Antonio Gramsci. Este primer objetivo se establece solamente para poner el piso necesario para el segundo objetivo, que consiste en desarrollar la afirmación de que el testimonio es una herramienta (entre otras) que se utiliza para romper las relaciones de dominación, pero no solamente porque el testimonio ha funcionado como puente inter-clase que genera simpatizantes en los lectores solidarios, sino porque el testimonio es una forma pedagógica que permite reflexionar críticamente sobre la propia práctica, aprender de otros, e inventariar la conciencia en un momento específico de la historia del sujeto social o individual. En una tercera parte planteo el caso de dos colectivos de mujeres mexicanas en lucha, que ejemplifican el uso político del testimonio de formas diversas, con el fin de mostrar cómo se ejercen en la práctica aquellas cuestiones que expongo teóricamente al inicio del texto. Por último, en las conclusiones propongo el término "acción testimonial” como alternativa a "género testimonial”, en una estrategia que pretende destacar la agencia del testimoniante y la performatividad del testimonio.

\section{Hable subalterno}

El vínculo entre el género testimonial y las clases subalternas, es casi un correlato en la producción teórica que revisa este género narrativo. La subalternidad se vincula al testimonio debido sobre todo a la manera en la que los estudios culturales y la teoría crítica, destacan como principal característica subalterna, su relación marginal con la historia, sobre todo a partir de la labor historiográfica de la Escuela de Estudios Subalternos (EES), que se sumó a la premisa de la historiografía marxista inglesa, emprendida por Eric Hobsbawn, Edward P. Thompson y George Rudé entre otros, que consistió en escribir una "Historia desde abajo" que pudiese "retar la univocidad del discurso estatista" (Guha,

\footnotetext{
${ }^{1}$ Marisol “Ex integrante de la Junta de Buen Gobierno. MAREZ San Pedro de Michoacán”, citado en bibliografía como: Frente Zapatista de Liberación Nacional (2013).
} 
1996: 11), devolviendo una posición de agentes a quienes también participaron en los eventos de la historia, pero fueron instrumentalizados, ocultados o negados por la narrativa dominante.

También bajo la corriente histórica "desde abajo", a partir de finales de la década de los setenta, académicos y periodistas comprometidos, se dieron a la tarea de entrevistar y recoger la narración de las diversas experiencias de lucha en los movimientos y levantamientos socialistas latinoamericanos. En 1977, el testimonio de Domitila Barrios de Chúngara, recabado, compilado y editado por Moema Viezzer es un ejemplo perfecto de una forma de producción narrativa que fue cobrando una relevancia literaria y política enorme hacia mediados de los años ochenta, cuando la teoría crítica y los estudios culturales se volcaron en el testimonio.

Bajo la recuperación de la "historia desde abajo", las clases subalternas fueron definiéndose no solamente de acuerdo a su posición en las relaciones de producción, sino de acuerdo a su capacidad de plasmar su proyecto y participación política en la narrativa del conjunto social, que se construye históricamente. Por tanto, se caracterizó como subalternos a quienes no aparecen en el relato de los grandes acontecimientos que dan forma a un Estado o a una sociedad determinada, y cuando aparecen, es siempre bajo la óptica de las clases dominantes, ya sea como vencidos, como actores secundarios, o como ejemplo para comprobar alguna tesis que sirve a los propósitos de la narrativa oficial.

Los historiadores de la EES se dieron a la tarea de "producir análisis históricos en los que los grupos subalternos fueran vistos como sujetos de la historia” (Chakrabarty, 2010: 30). De estos análisis históricos, centrados en la experiencia de las resistencias campesinas indias a la colonia británica, surgieron importantes trabajos que dieron origen a una ola de reflexiones y nuevas teorizaciones sobre la subalternidad, y sobre las posibilidades, formas, contradicciones y problemas de rescatar su historia y voces.

En "La pequeña voz de la historia" (1996), texto que introduce a la novena publicación de Subaltern Studies, Guha no menciona directamente a la forma testimonial como un medio para conseguir la emergencia de la voz subalterna, pero construye su caso a partir de "una serie de entrevistas grabadas como material para una lectura feminista" (Guha, 1996: 8), realizadas a mujeres que participaron en el levantamiento de Telangana, cuyas reivindicaciones terminaron fuera del programa político, y cuya participación tampoco fue tomada en cuenta en la saga resultante, hasta que finalmente las jóvenes estudiosas que las entrevistaron pudieron registrar "un sub tono de acoso, y una nota de dolor, que las voces de las mujeres mayores expresan, para que las jóvenes las escuchen” (Guha, 1996: 8-9). Esta forma de registro de la experiencia subalterna, intermediada por investigadores comprometidos, sin duda es una de las características que marcó al género testimonial, y se convirtió en uno de sus nudos más problemáticos: 
Mariana Espeleta. Testimonio y subalternidad hoy...

Estas son pequeñas ${ }^{2}$ voces sofocadas en el ruido de los mandatos estatistas. Es por eso que no les escuchamos. También es por ello que debemos hacer un mayor esfuerzo, desarrollar ésas habilidades especiales, y sobre todo cultivar esa disposición para escucharlas e interactuar con ellas. Pues tienen muchas historias que contar; historias que por su complejidad son incomparables al discurso estatista, y de hecho opuestas a sus formas abstractas y sobre simplificadas (Guha, 1996: 3).

En el planteamiento realizado por Guha, se evidencian una serie de problemas relacionados con la idea de que el discurso subalterno -en este caso visible a través del testimonio- está en oposición del discurso hegemónico. Así, el testimonio del subalterno sería comprendido como la otra cara de la Historia dominante.

Para el caso que nos ocupa, esta noción de oposición es problemática porque implica muchas presuposiciones respecto a la subalternidad, que resultan en cuestiones irresolubles cuando se pretende teorizar sobre el testimonio.

En primer lugar, en muchos textos académicos existe una total asimilación entre los términos "hegemónico" y "dominante”. Para comprender la diferencia (y su importancia en este asunto) me voy a remitir al pensamiento de Antonio Gramsci, particularmente a varias nociones referidas de manera dispersa a lo largo de su extensa obra conocida como "Cuadernos de la cárcel”. La dominación es una fuerza unidireccional que se aplica coercitivamente; en la dominación el sujeto activo es el dominante, los dominados son pasivos. La hegemonía en cambio, es un fenómeno de consenso y coerción que produce un efecto de aceptación y resistencia; las clases dominantes son aquellas que han conseguido posicionar sus intereses, como proyecto de la sociedad en su conjunto, y las clases subalternas son quienes han asumido (y a la vez rechazan) ese proyecto como propio. Entre las clases dominantes y las clases subalternas hay un complejo entramado de proyectos e intereses, también hay una gama de clases intermedias.

Bajo esta lógica gramsciana, el discurso subalterno no es el que se opone al discurso hegemónico: el discurso subalterno, incorpora al discurso hegemónico en algunos aspectos y al mismo tiempo lo rechaza en otros. En la relación dicotómica subalterno/hegemonía que se deriva de la perspectiva de Guha, las voces de los subalternos no son escuchadas porque los agentes de la historia, o sea las clases dominantes, no las toman en cuenta. Por esta razón, tal como establece en el párrafo arriba citado; se requiere de la intermediación "debemos hacer un mayor esfuerzo", dice Guha, y con ello suponemos que el sujeto implícito somos unos "nosotros", que hemos brotado mágicamente en algún limbo que no

\footnotetext{
${ }^{2}$ Algunos traductores (como los que realizaron la edición aparecida en ed. Crítica, Barcelona, 2002) de este trabajo al castellano, omitieron el adjetivo "pequeñas" quizá por no ser del todo correcto, sin embargo decidí (siguiendo a otros como Iliana Rodríguez) utilizarlo tomando en cuenta que la pequeñez hace alusión tanto a una escala de volumen sonoro como en términos de tamaño y significación frente al poder del estatismo.
} 
pertenece a ninguna de las dos polaridades subalterno/dominante. De hecho, este "nosotros" se hace cuanto más oscuro, si revisamos la definición que hizo el propio Guha de los grupos subalternos de la india: "Los elementos y grupos sociales incluidos en esta categoría, representan la diferencia demográfica entre el total de la población india, y todos aquellos que hemos descrito como la élite (Guha, 1998: 44, cursivas en el original)".

Para la teorización del testimonio, el intermediario (nosotros) es muy problemático si lo planteamos como neutralidad, pues esto resulta en una ficción evidente: no hay nadie que no pertenezca al ordenamiento social. De allí que, si como señala Guha en el párrafo arriba citado, solamente existen dos clases opuestas, una de ellas "los subalternos" cuya característica específica es su incapacidad para hacerse escuchar, y la otra clase que llama “élite” ¿Dónde se ubican estos sujetos que han de rescatar las voces de los subalternos, traducirlas y hacerlas audibles? La única respuesta posible, sería que -en tanto podemos efectuar el rescate- formamos parte de la élite. El efecto resultante, sería que el rescate es por tanto una impostura, idea que Gayatri Spivak trabajó brillantemente en su conocidísimo ensayo Can the subaltern speak?

En este texto, Spivak identifica dos formas de lo que ella misma llama "violencia epistémica”. Una, que es característica de la historia dominante es la de hablar de los subalternos, sin tomarlos en cuenta, tal como ya referí al inicio de este trabajo. La segunda es la de hablar por los subalternos suplantándolos, o interpretándolos desde una perspectiva interesada -consciente o no- que termina igualmente por ocultarlos. A ésas voces que nunca logran emerger, Spivak las califica de "espacio en blanco" un "espacio inaccesible circunscrito por un texto interpretable” (Spivak, 2003: 337). El resultado sería que el subalterno estaría en una total imposibilidad de enunciación de la cual no podría escapar.

Las implicaciones de ambas posturas, es que la iniciativa histórica queda de manera inexorable en las clases dominantes, despojando de toda agencia a las clases subalternas. Además, al pensar que la subalternidad es la posición opuesta de la hegemonía (entendida como mera dominación), siempre y cuando el orden que establece cada una de estas posiciones se mantenga, los subalternos serían una formación estática.

\section{El testimonio de su clase para sí}

Desde la teoría gramsciana las clases subalternas lo son en tanto permanecen bajo el consenso y la iniciativa de las clases dominantes. La posibilidad de agencia de los subalternos requiere que se conjuguen una serie de condiciones económicas y sociales, a la vez que un proceso de subjetividad, que permitan producir conciencia de clase, pensamiento crítico, y lo que el filósofo llama "dirección consciente". Así, la marginalidad histórica es producto de la falta de herramientas políticas de una clase, 
la carencia de estrategia y visión a largo plazo que les impide sospechar "... siquiera que su historia pueda tener alguna importancia y que tenga algún valor dejar rastros documentales de ella (Q3, §48: 51-52) ${ }^{3 \%}$.

Aunque la historia de las clases subalternas tenga un propósito contestatario o resistente a una versión de la narrativa dominante, el relato subalterno está marcado por la doble relación de aceptación y resistencia a la hegemonía. Por esta razón, la versión subalterna de la historia puede ofrecer un punto de vista excéntrico y distinto de una versión oficial, pero no necesariamente contrapuesto y más comúnmente, incorporará rasgos y elementos del discurso de los grupos dominantes. Sin embargo como establece Gramsci en el Cuaderno 3, en la medida en que las clases subalternas emprendan el complicado camino hacia la autonomía, aumentará su agencia histórica, su actividad será menos reactiva de la iniciativa de las clases dominantes, menos aislada y menos episódica; mientras que la conciencia histórica hará posible la emergencia de formas narrativas propias, será recopilada con cada vez menor necesidad de intermediación, y finalmente devendrá en una historia propia, de su clase para sí.

Al punto que quiero llegar, es que al no tomar en cuenta estas cuestiones, y al quedarse en la simplificación del binomio subalterno-dominante, resulta fácil caer en el error de pensar que la conciencia subalterna está en una posición de privilegio para develar una verdad emancipadora, que lo único que requiere es un podio, un micrófono -y que pongamos atención, hagamos un esfuerzo, etc.- y la dominación quedará rota. En otras palabras, que el testimonio subalterno contiene en sí mismo la experiencia contraria a la experiencia hegemónica. Elzbieta Sklodowska, lo expone claramente:

La premisa teórico-estratégica subyacente de todos los testimonios es la marginalidad de ciertos sujetos y de la necesidad de hacerlos hablar y ser oídos; consecuentemente, la conciencia marginal queda privilegiada como la más idónea para reescribir la historia y reevaluar el presente (Sklodowska, 1992:51).

Por supuesto, este razonamiento no va encaminado a despojar al testimonio subalterno de su valor, sino a cambiar el foco de su interés. Si comprendemos la subalternidad como una posición que se establece por medio de una correlación de fuerzas en tensión y dinamismo constante; y entendemos que la conciencia subalterna no es estática, no es esencial, no es transparente y no es inmediata; entonces debemos asumir que el registro de la experiencia sirve para dar cuenta de cuál es la posición del sujeto en un momento determinado y sirve como registro de la conciencia, insumo indispensable para aquello que Gramsci llamó “catarsis”, es decir un movimiento inicial de ruptura con la hegemonía por medio de una transformación subjetiva que permite ir identificando en sí mismo los valores, tradiciones, creencias, costumbres, etc.; que provienen de la asimilación hegemónica, y perpetúan la propia subalternidad:

\footnotetext{
${ }^{3}$ Para citar a Gramsci, Utilizo el formato de citación establecido por Valentino Gerratana, que clasifica el número de cuaderno (Q), el número de nota (§), y la página de la edición citada. En este caso para el Cuaderno tres es el “Tomo 2” (1981) y para el Cuaderno 11, es el “Tomo 4" (1986), todos de la única edición en Español de los cuadernos completos, editados por ERA.
} 
Mariana Espeleta. Testimonio y subalternidad hoy...

El inicio de la elaboración critica es la conciencia de lo que es realmente, o sea un "conócete a ti mismo" como producto del proceso histórico desarrollado hasta ahora que ha dejado en ti mismo una infinidad de huellas recibidas sin beneficio de inventario. Hay que hacer inicialmente ese inventario (Q11, §12: 246).

En el párrafo arriba citado, Gramsci no se refiere a la forma testimonial, pero está claro que para teóricos como Beverley (1993) o Yúdice (2002), el testimonio cumple esta importante función, no solamente como "inventario" de la conciencia individual, sino también de una subjetividad colectiva en formación. En este sentido, el testimonio es una marca en un mapa; una instantánea tomada en pleno movimiento, cuyo valor de análisis no es solamente académico, sino político: ¿Cuáles son los elementos hegemónicos incorporados que deben superarse en esta conciencia que retrata el testimonio? ¿En qué momento de consenso o de resistencia se ubica? Más adelante retomaré este punto en términos de por quiénes y desde dónde deben ser realizados dichos análisis.

Sin embargo, el testimonio no solamente es un recuento de la subjetividad, ni de las reflexiones propias. También es la narración de lo vivido, del suceso colectivo, de los agravios padecidos, las acciones emprendidas, las pérdidas, los encuentros y las divergencias. Este aspecto más factual, ha sido el vórtice de innumerables discusiones académicas relacionadas con la veracidad de los recuentos testimoniales, que en gran medida recaen también en la figura del gestor o intermediario. Para complicar más el asunto, el testimoniante a menudo refiere cosas que no necesariamente vivió ni vio, pero que sabe de cierto que sucedieron, según su propio criterio de veracidad. Así, en la crítica literaria dedicada al testimonio abunda la búsqueda de contradicciones y ambigüedades. Se intenta transparentar el relato, separar lo verdadero de lo falso, comprobar los hechos, y descubrir la manera en la que gestores y editores intervienen en el texto para ordenarlo y modificarlo. Más aún, durante toda la producción testimonial, un tercero también interfiere como mediador; se trata del destinatario que podrá ser una antropóloga, una juez, un ciudadano solidario del primer mundo, quienes para ser alcanzados requieren de una forma y contenido narrativo que a menudo es alterado o refinado, haciéndolo apto para su consumo:

Evidentemente los problemas sui generis del testimonio mediato surgen en la encrucijada de los códigos del editor y del interlocutor. Los retratos de los testigos quedan doblemente retocados: primero por ellos mismos, luego por sus respectivos amanuenses. Montejo y Rigoberta decodifican sus propias culturas, pensando tanto en sus interlocutores inmediatos como en el lector potencial, pero la (re)codificación definitivamente está a cargo del editor. De ahí que el concepto del destinatario virtual juegue un papel crucial en este proceso de (re) codificación. Obviamente, se trata aquí de un "contrato" y el destinatario del testimonio tiene que ser parte integral de nuestras consideraciones (Sklodowska, 1992: 137).

Sucede entonces algo muy extraño: mientras el testimoniante y su editor recodifican lo que narran según el destinatario que tienen en mente, los consumidores especializados buscan romper ese código 
para encontrar una supuesta verdad que se esconde detrás del artificio, o bien para encontrar la falsedad y desmentir al testimoniante $\mathrm{o}$ al editor.

Esta cadena de producción testimonial, produce dos situaciones que considero perversas: por un lado, implica que la única forma de testimonio digna de ser trabajada y estudiada proviene de la periferia, y es un producto cultural manufacturado para consumo del centro; por otro lado, que el testimonio oculta una esencia (ya sea del sujeto o de los hechos que narra), una verdad que se esconde pero resulta en una gran lección para occidente, y la obtendrá el caza tesoros que logre desentrañarla.

Así, pareciera que la crítica y la academia fuesen incapaces de ver que existe el testimonio más allá del que se produce para su consumo, y bajo las normas de un producto apto para su mercado. Sin duda, alguno o todos los receptores arriba mencionados son los destinatarios principales de los testimonios que han sido recogidos y publicados precisamente por académicos, y funcionarios de instituciones para llevar la palabra subalterna a sus ámbitos de acción. Sin embargo, el testimonio también existe aunque nadie esté allí para registrarlo-traducirlo-editarlo-imprimirlo-distribuirlo. Quizá el problema radica en la consideración del testimonio como género literario.

No cabe duda que hasta hace relativamente poco, existían pocas probabilidades de transmisión efectiva más allá de la escritura, y si el testimonialista era iletrado o ni siquiera hablaba una lengua mayoritaria, necesariamente requería de un representante que le sirviese de médium para poder hablar con estos interlocutores, y más frecuentemente los interlocutores requerían de un médium para hacer hablar al subalterno. Hoy en día es necesario replantear si el género testimonial rompió ya la barrera de la intermediación/ representación cuando es posible registrarlo y diseminarlo de formas mucho más inmediatas en tiempo y recursos que cuando existía de forma exclusivamente literaria ${ }^{4}$.

La cuestión del destinatario también debe ser revisada a profundidad, pues en gran medida el testimonio que surge de los nuevos movimientos sociales se inserta en una lógica novedosa y propia que está profundamente relacionada con estas formas tecnológicamente accesibles de distribución; y que no necesariamente se dirige ni a los estudiosos, ni a las clases dominantes, ni las instituciones encargadas de administrar recursos y justicia. De hecho, incluso sin los nuevos medios de registro y distribución, en América Latina existe toda una red de producción y registro testimonial para el autoconsumo o la articulación solidaria que requiere de acción inmediata. George Yúdice zanja la cuestión de la veracidad factual de la siguiente manera:

El testimonio no responde al imperativo de producir la verdad cognitiva -ni tampoco de deshacerla- su modus operandi es la construcción comunicativa de una praxis solidaria y

\footnotetext{
${ }^{4}$ Respecto a al replanteamiento de la relación entre literatura y testimonio, ver el texto de George Yúdice (2002) citado en la bibliografía.
} 
emancipatoria. De ahí que la dicotomía verdad/ficción carezca de sentido para comprender el testimonio (Yúdice, 2002: 231).

Por supuesto, no se trata de negar que el testimonio opera bajo la premisa de que los hechos que narra forman parte de la experiencia verdadera del sujeto, y lo que allí se evoca como vivido no es ficticio, sino dejar de anteponer lo factual como el aspecto medular de esta forma narrativa.

Un buen ejemplo de lo que Yúdice llama "paraxis solidaria y emancipatoria”, puede observarse en los encuentros que sostienen los miembros del Frente Zapatista de Liberación Nacional (FZLN), con otros colectivos que están en lucha en México, Latinoamérica y otras partes del mundo. En estos encuentros, existen espacios para que los asistentes den su testimonio ante los demás, y se les llama “comparticiones”, resaltando la horizontalidad y la reciprocidad implícita:

La palabra compartición no existe en los diccionarios, aunque se anuncia que se incluirá en la $23^{\text {a }}$ edición del de la Real Academia Española. En ese diccionario la definición será: “Acción y efecto de compartir". Pero para los zapatistas y los pueblos indígenas la compartición es algo mucho más profundo y tiene un sentido político. Para entenderlo, habría que escribir un ensayo. O no. Para entenderlo, hay que practicar la compartición, cueste lo que cueste (Reyes, 2014).

Los testimonios que se brindan en las comparticiones tienen el propósito de dar cuenta de las experiencias de opresión, los procesos de organización y resistencia; y las reflexiones que van trazando la formación subjetiva de quién comparte su narración:

Compartición es el encuentro de dolores y rabias en un país que se desmorona, en un país poblado de horrores en que la indignación acumulada finalmente se desborda y sale a las calles ante los asesinatos y desapariciones cometidas por el narcoestado contra los normalistas de Ayotzinapa. Pero compartición es también el encuentro de dignidades y de alternativas de vida ante la muerte impuesta desde el poder (Reyes, 2014).

La cita con la que inicia este artículo, es una fracción del testimonio de Marisol, rendido en una “compartición” de mujeres ${ }^{5}$, cuyo tema fue la experiencia respecto a su participación social y política en las comunidades zapatistas, y la evaluación de los avances y dificultades a los que se han enfrentado las mujeres para conseguir la igualdad, desde que en 1994 se declaró el levantamiento y se publicó la Ley Revolucionaria de Mujeres. Elegí ese fragmento para ilustrar la existencia publicada y accesible de una forma testimonial que no ha pasado por la intermediación de ningún gestor, y cuyo problema no es la traducción al "castilla", sino a las diferentes lenguas que hablan las mujeres zapatistas según su región: Tzeltal, Tzotzil, Tojolobal o Zoque, con el fin de que puedan comprenderse entre ellas.

\footnotetext{
${ }^{5}$ Las participaciones completas fueron recogidas en el cuaderno "Participación de las mujeres en el gobierno autónomo“, una autoedición elaborada junto con otros cuadernillos temáticos para el encuentro celebrado en agosto de 2013 en las montañas de Chiapas, que se llamó "Escuelita zapatista", en el que participaron diversas organizaciones y movimientos sociales de México y otras partes del mundo. Este cuadernillo está citado en la bibliografía como Frente Zapatista de Liberación Nacional (2013), y disponible en el enlace citado.
} 
La existencia de las “comparticiones", su propósito, sus formas de registro y distribución, rompen por completo el esquema del testimonio que ha sido trabajado y discutido tradicionalmente por la academia. En internet también es posible encontrar testimonios registrados en video, donde de viva voz la testimoniante transmite su experiencia sin editar:

Fui nombrada por todas mis compañeras para traerles la palabra de ellas, para que sepan ustedes como hemos enfrentado nuestra lucha en la construcción de nuestra autonomía... antes de 1994 nos han tratado muy mal, nos han tratado como animales, en las calles de la ciudad... y como mujeres hemos sufrido en varias formas durante muchos años hemos sufrido 3 veces más la humillación y el desprecio... Como mujeres zapatistas estamos luchando para demostrar que si somos capaces de decidir sobre nuestras vidas, que si podemos sacar adelante a nuestros hijos, no necesitamos a un profesionista a que nos venga a decir cómo debemos vivir. Gracias a nuestra lucha que nos dio un lugar digno como mujeres indígenas, hemos aprendido muchas cosas... No estamos dispuestas a humillarnos, también a nuestros propios compañeros que han entendido que tenemos los mismos derechos (EZLN, 2006) ${ }^{6}$.

Respecto a las comparticiones zapatistas, su razón de ser y su registro, me interesa revisar la posición de la subjetividad de los testimoniantes. Encuentro en el mero hecho de organizar estos eventos, transcribir sus contenidos y hacer grabaciones, un emprendimiento ya encaminado hacia la autonomía. El mensaje de las comparticiones no tiene como destinatarios a públicos abstractos, académicos lejanos ni instituciones del llamado "mal gobierno". El testimonio es la vivencia propia que se comunica como construcción de subjetividad en lucha y propósito de articulación con otros iguales, con aliados que se desplazan a recibir la compartición, o con un público activo que busca las comparticiones en los medios de difusión zapatista. La compartición tiene un carácter pedagógico doble: por un lado permite aprender de la propia experiencia y hacer el recuento de este aprendizaje; y por otro, introduce los destinatarios en formas de hacer y de pensar, otras. También transmite la experiencia de opresión particular en tanto mujeres, en tanto indígenas, en tanto campesinas, en tanto pobres... Pero sobre todo transmite las formas de dignidad y alternativas de vida nuevas y propias. De todo esto se aprende al presenciar o leer una compartición. En el caso de las zapatistas, queda claro que no estamos ya frente al sujeto subalterno de Guha ni de Spivak. Estamos frente al sujeto en tránsito que visualiza Gramsci; lo que retratan las comparticiones es la huella de un desplazamiento. En la recopilación completa, pude apreciarse la manera en la que las mujeres zapatistas están todavía luchando contra los elementos regresivos incorporados de las comunidades donde se insertan, realizando un "inventario" de aquellas prácticas de subordinación que siguen instaladas en ellas mismas y en sus compañeros.

\footnotetext{
${ }^{6}$ Fragmento trascrito de un testimonio (anónimo) en vídeo, ofrecido en el marco de la llamada "Comisión intergaláctica del EZLN”, celebrada en 2006. Citado en la bibliografía como: Ejército Zapatista de Liberación Nacional (2006). Se puede ver en línea: https://www.youtube.com/watch?v=_bGI9gMbrxk.
} 
Por supuesto, la función de articulación social del testimonio, sigue centrada en la construcción de alianzas estratégicas. Esto es particularmente posible de observar cuando dejamos de lado la idea de la dicotomía polarizada subalterno/dominante -donde se haría difícil buscar aliados fuera de la propia clase-; pues al comprender la subalternidad como posición relacional entre una variedad múltiple de otras posiciones e intereses, se evidencia claramente la posibilidad de sumar y movilizar a otras clases en una meta común o solidaria. En este campo de alianza me parece importante ubicar nuevamente a los gestores/editores (cuando los hay), y a los destinatarios de quienes se esperan respuestas y acciones concretas, no solamente lecturas y empatía. La pregunta sobre cómo se transforma la subjetividad de los destinatarios del testimonio es absolutamente relevante y se trabaja poco, pero sin duda es posible afirmar que en mayor o menor medida los testimonios son una forma de despertar conciencias y llamar a la acción.

\section{Dos casos de mujeres en México}

$\mathrm{Al}$ inicio de este texto me posicioné como cercana a las realidades desde las cuales se producen testimonios subalternos, refiriéndome particularmente a mi trabajo relacionado con colectivos de mujeres mexicanas en lucha. La cercanía a la que me referí es primeramente emocional, en segundo término política, y en tercer lugar académica. Específicamente voy a hablar de las madres de las mujeres desaparecidas y asesinadas en Ciudad Juárez, y de un colectivo de veracruzanas conocido como "las Patronas", en el caso de ambos grupos, el testimonio ha sido una parte fundamental y multifacética de su acción política y de la conformación de su identidad.

Resalto en primer lugar el aspecto emocional, pues como bien lo afirma la crítica literaria, el testimonio produce respuestas afectivas en los receptores. Sin embargo, en ninguno de los dos casos los testimonios de estas mujeres han sido recogidos con un propósito literario o estético; nacieron de la necesidad o de la curiosidad mediática, están registrados en documentos jurídicos o en blogs personales, en entrevistas periodísticas, en documentales, y en el caso de las madres de Juárez, algunos de estos testimonios se recogen en libros de investigación como "Huesos en el desierto" (2002) de Sergio González Rodríguez o "Cosecha de mujeres: safari en el desierto mexicano" (2005) de Diana Washington Valdez (citados), que están sobretodo centrados en los casos de desapariciones, asesinatos y negligencia del Estado mexicano, que en los testimonios en sí mismos. 
Existen también algunos testimonios recogidos en trabajos académicos, de diversa índole y de gran interés, pero prácticamente no hay nada dedicado exclusivamente a darles un tratamiento literario ${ }^{7}$. Respecto a las Patronas no existe bibliografía, aunque tienen una abundante cobertura mediática y de prensa, sus discursos o historias personales no se han recogido en ningún trabajo académico ${ }^{8}$ o editorial.

El caso de las madres de las asesinadas y desaparecidas en Ciudad Juárez, Chihuahua, México ${ }^{9}$, es parecido al de otros movimientos sociales de madres en el mundo, que buscan a sus hijos e hijas desaparecidos durante conflictos armados, periodos de violencia política o dictaduras, como las muy conocidas argentinas "Madres de Plaza de Mayo". La particularidad del caso Juárez tiene que ver con una cuestión de género inédita: las víctimas desaparecidas y asesinadas son específicamente mujeres, las desapariciones están directamente relacionadas con el fenómeno del feminicidio sexual sistémico (Monárrez, 2009), y comenzaron en un contexto que no estaba declarado ni como zona en conflicto ni sometido a violencia política. La intención de este trabajo no es desarrollar una panorámica de estos hechos terribles, sino revisar algunos aspectos relevantes del papel que jugó el testimonio de estas mujeres, como herramienta política.

En un inicio, cuando iniciaron las desapariciones, las madres de estas jóvenes acudían de manera individual a la policía que las ignoraba, argumentando que era probable que las chicas hubiesen desaparecido por su propia voluntad. Al paso del tiempo y con la aparición de cuerpos en el desierto, las mujeres sospecharon de contubernio de las autoridades, y denunciaron la posibilidad de estar frente a un siniestro fenómeno colectivo. Las mujeres recurrieron a los testimonios de viva voz para transmitir su desesperación y su dolor, ante la inacción de las autoridades locales que se negaban a reconocer el problema, y mucho menos a investigar las desapariciones de manera diligente y científica ${ }^{10}$. En pequeños

\footnotetext{
${ }^{7}$ La única referencia que he encontrado en este sentido, está citada en el excelente trabajo de Laura Segato (2006) "La escritura en el cuerpo de las mujeres asesinadas en Ciudad Juárez: territorio, soberanía y crímenes de segundo estado" (citado), se titula: "El silencio que la voz de todas quiebra. Mujeres y víctimas de Ciudad Juárez”, por: Rohry Benítez, Adriana Candia, Patricia Cabrera, Guadalupe de la Mora, Josefina Martínez, Isabel Velázquez, Ramona Ortiz; Ediciones del Azar/Taller de Narrativa, Chihuahua, México, 1999. Un libro que no he podido conseguir, posiblemente una edición limitada para consumo local.

${ }^{8}$ En mi trabajo: Espeleta, 2015 (citado), dedico un capítulo a "las Patronas" que no está centrado en la producción testimonial sino en su proceso de subjetivación política.

${ }^{9}$ En los años noventa, comenzó a hacerse del dominio público la desaparición y asesinato sistemático de mujeres jóvenes en esta ciudad fronteriza de México. A la fecha no existe un conteo fidedigno pero las víctimas podrían superar el millar. Los familiares y personas cercanas a las desaparecidas y asesinadas, particularmente sus madres, se han auto-organizado para buscar a sus hijas y reclamar justicia. Han surgido una gran diversidad de actores -ONG, académicos, y movimientos no institucionalizados- y voces -locales, nacionales e internacionales- que han denunciado la problemática desde muchas perspectivas, han intervenido con acciones políticas, y mediado entre las víctimas y los procesos.

${ }^{10}$ Todas las investigaciones del caso, enfatizan en esta situación, para mayores detalles puede consultarse la bibliografía citada de González (2002) o Washington (2005). Este fenómeno también se recoge en términos jurídicos en la Sentencia de la Corte Interamericana (2009), citada.
} 
foros improvisados, en eventos autogestionados y en espacios públicos, las madres de las víctimas exponían su historia con un cartel y una fotografía, hablaban de sus hijas, sobre el día en que desaparecieron y contaban a quien quisiera escucharlas todos los agravios y omisiones que las autoridades cometieron en su contra (Ravelo 2004). Así fue como se conocieron unas a otras, y así fue como se sumaron académicas y activistas locales que las ayudaron a iniciar la terrible batalla que aún no concluye.

En noviembre de 2004, gracias al apoyo solidario de organizaciones locales, y activistas internacionales, cinco madres y una hermana de víctimas del feminicidio, emprendieron una caravana llamada Caravana Internacional por la Justicia en Ciudad Juárez y Chihuahua, que recorrió 53 ciudades de Canadá y Estados Unidos hasta retornar a Ciudad Juárez. La Caravana fue acompañada por académicas norteamericanas, organizaciones de migrantes y defensores de los Derechos Humanos. Se organizaron eventos públicos donde se proyectaron documentales y se rindió testimonio, ruedas de prensa, conferencias y encuentros con actores relevantes. La cobertura mediática fue masiva, y de esta y otras caravanas surgieron diversas acciones solidarias y extrañamientos de la sociedad norteamericana hacia las autoridades de Juárez y del Estado Mexicano ${ }^{11}$.

En el año 2005, Marisela Ortiz ${ }^{12}$ emprendió una gira por Alemania en la que recorrió 15 ciudades donde expuso la situación de las madres que buscan a sus hijas, y presentó documentales que recogen los testimonios de las madres y su lucha:

La impresión que me queda es que muchos alemanes no conocían el problema y que el presenciar los testimonios estremeció a muchos corazones. Para mucha gente en Alemania era imposible entender por qué tanta impunidad. ¿Por qué la policía, que debe proteger, asesina mujeres?, se preguntan. Esto ha sido de verdad muy impactante para ellos (Ortiz, 2005).

A partir de esta gira, las organizaciones de madres en México consiguieron generar bastante presión política sobre el problema en Ciudad Juárez, y recibieron apoyos concretos de organizaciones como la Universidad Libre de Berlín y la Liga Internacional de Mujeres por la Paz y la Libertad. A más largo plazo, la solidaridad nacional e internacional ha ejercido enorme presión sobre el Estado mexicano, y ha financiado a las organizaciones de madres de muy diversas maneras, en algunos casos ha facilitado

11 Un informe más amplio sobre las acciones y resultados de la gira puede obtenerse en el Informe presentado por la organización "Mujeres en Red”, disponible en:

http://www.mujeresenred.net/IMG/article_PDF/article_a108.pdf .

12 Es fundadora de la organización "Nuestras hijas de regreso a casa” (NHRC). Fue profesora de Lilia Alejandra García Andrade (desaparecida a los 17 años, el 14 de febrero de 2001, encontrada sin vida). Ha sido vocera y presidenta de NHRC, su activismo se ha centrado en denunciar la red de corrupción y connivencia con el crimen organizado de las autoridades, y en difundir el análisis de los casos desde una perspectiva de género que denuncia el sexismo estructural. 
los procesos de asilo político que algunas de las familias y defensoras de las asesinadas y desaparecidas han tenido que solicitar ${ }^{13}$.

Patricia Ravelo Blancas, una de las pocas investigadoras que se ha dedicado a trabajar los aspectos de la subjetividad de las madres de las asesinadas y desaparecidas, señala que para las organizaciones de mujeres ha sido de gran relevancia la respuesta emocional de las oyentes de sus testimonios. Recalco el femenino en tanto que las mujeres se refieren a menudo a otras mujeres, como quienes les manifestaron un mayor apoyo, particularmente enfatizando la maternidad como vínculo de identificación (Ravelo, 2010). A este respecto, tomo la cita de Evangelina Arce, madre de Silvia Haro Arce que desapareció en marzo de 1998 a los 27 años, y hasta la fecha no ha sido localizada:

Se arrimó una señora de Virginia... me dice: "qué puedo hacer por ti, yo siento mucho lo que ha pasado con tu hija y que no se haya hecho nada, dijo, si tienes volantes, recortes -Mi hija casi nunca ha salido en el periódico-. Yo también me llamo Silvia (continuó esta señora) y a mí me duele mucho si no están haciendo nada, qué puedo hacer yo acá para poder seguir hablando de tu hija con volantes y sacar lo que tú hablas o dices para ver si así podemos sacar algo"... (En: Ravelo, 2010: 53).

El testimonio de viva voz establece lazos imposibles para el testimonio literario, porque permite la retroalimentación de las emociones entre el testimoniante y el receptor, sin intermediarios, y facilita la toma de postura política, las alianzas, y las acciones inmediatas. El asunto de los feminicidios en Juárez está lejos de resolverse. Hoy en día, la situación en México es aún más complicada de lo que era a finales de los años noventa, pues la violencia de los cárteles, del crimen organizado y la corrupción de las instituciones se han extendido sin control, y el número de víctimas en general y de feminicidios en particular, aumentaron en todo el país ${ }^{14}$. Muchas de las madres de desaparecidas y asesinadas en Juárez no han encontrado justicia, aunque en el año 2009, la Corte Interamericana de Derechos Humanos emitió una sentencia histórica -la primera- en contra del Estado Mexicano, y su responsabilidad en los crímenes de Juárez. El testimonio de las madres fue fundamental para probar la negligencia, las múltiples faltas en la administración de justicia y el encubrimiento del Estado.

Aunque el testimonio jurídico es de naturaleza diferente que el testimonio literario y está constreñido a las formas de un proceso legal, opera de manera similar en términos de la intermediación y

\footnotetext{
${ }^{13}$ Para conocer más sobre las relaciones de solidaridad transnacional que han construido las organizaciones de madres de las mujeres muertas y desaparecidas de Juárez y Chihuahua, se recomienda consultar: Aikin, Olga (2011) Activismo social transnacional. Un análisis en torno a los feminicidios en Ciudad Juárez, México: COLEF; o Ravelo Blancas, Patricia (2004), citado.

14 Para conocer más del estado actual de esta situación en México, se puede consultar el reciente informe de Amnistía Internacional (14 de enero 2016): "Un trato de indolencia, La respuesta del Estado frente a la desaparición de personas en México”, disponible en línea en: http://amnistia.org.mx/nuevo/wp-content/uploads/2016/01/ AMR_4131502016_SP.pdf. 
la posición privilegiada de los receptores. Sin embargo, en este caso particular el testimonio de viva voz rendido en las audiencias de la Corte Interamericana, finalmente la única autoridad que escuchó a estas mujeres, es posible gracias al trabajo incansable de toda una red social tejida en torno a los testimonios que incansablemente fueron otorgados de viva voz y difundidos por una multiplicidad de medios disponibles entre ellos el vídeo documental, tanto profesional como amateur ${ }^{15}$.

El segundo caso del que quiero hablar, es el caso de "las Patronas de Veracruz" porque es paradigmático como ejemplo de un modo novedoso y complejo de forma testimonial. Las Patronas son un grupo de mujeres campesinas, originarias del pueblo Guadalupe de la Patrona, en Amatlán, Veracruz. Viven del cultivo de la caña azucarera y el café, mal pagados para los pequeños productores, muy por debajo de los precios de los productos ya procesados en el mercado. Por el Pueblo de estas mujeres, pasa un tren que viene del sur de México y llega hasta la frontera norte.

Los migrantes centroamericanos sin papeles, en tránsito por México, montan en este tren y viajan entre los vagones o en el techo. Además de la constante amenaza por parte del crimen organizado, el acoso de las autoridades migratorias y el peligro de caídas o mutilaciones, los migrantes pasan hambre y sed en su trayecto. En 1995, una familia de Amatlán, las hermanas Romero Vázquez y su Madre Leonila Vázquez, comenzaron a ayudar a las personas que viajaban en el tren, arrojándoles bolsas de comida y agua. Otras mujeres de la comunidad fueron uniéndose, y así comenzaron una labor humanitaria que hoy en día es reconocida nacional e internacionalmente. El proceso de subjetivación política de estas mujeres es complejo, pues implica un largo proceso de 20 años, en el que han transitado de la acción reactiva en una lógica de caridad cristiana, a la defensa activa de los derechos de los migrantes en términos mucho más amplios, en sinergia con otras organizaciones, y en conciencia del problema en relación con el capitalismo y los procesos globales que fuerzan a la gente a trasladarse de sus lugares de origen buscando sobrevivir.

El trabajo de las Patronas se mantuvo en el desconocimiento público hasta el 2006, año en el que el documental "De Nadie" ganó el premio del público en el Sundance Film Festival. Este documental grabado por estudiantes sin experiencia, que llegaron por casualidad a Amatlán y en el que entrevistan brevemente a las mujeres, llamó la atención de algunos periodistas que hicieron modestos reportajes.

A esta primera incursión siguieron otros trabajos documentales que despertaron mayor curiosidad. En 2009, el fotógrafo y Reportero Javier García, y Lizette Argüello que había participado en la producción del primer documental, grabaron "La Patrona”, que prácticamente sin diálogo, relata en pocos minutos la preparación de la comida en las cocinas particulares de las campesinas, la transportación hasta las vías,

\footnotetext{
${ }^{15}$ Existe un sinnúmero de documentación de madres de asesinadas y desaparecidas que narran la historia de sus hijas y su búsqueda, accesibles en canales de vídeo. Entre ellas podemos mencionar "Señorita extraviada" (2001) o "Bajo Juárez" (2006), citados en la bibliografía. 
y el momento en el que pasa el tren y la arrojan a cientos de migrantes que se descuelgan de los vagones para coger las bolsas.

Las imágenes de las Patronas -más que sus palabras- produjeron una reacción en cadena entre la prensa, la sociedad civil y otras organizaciones en defensa de los migrantes. A partir de 2010 es posible encontrar una abundante producción de artículos periodísticos, fotografías y vídeos sobre ellas en internet. En estos registros conviven la mirada de quienes los realizan -como intermediarios- y la voz e imagen de las Patronas. Su testimonio como tal, nunca ha sido recabado con propósitos literarios o académicos, pero ellas mismas tienen un blog (citado) en el que suben a la red algunas de sus anécdotas, todas sus comunicaciones oficiales y sus discursos.

A la par de este activo fenómeno de registro, las Patronas se encontraron con la conciencia del impacto social de su labor, y el impacto de su labor en su propia subjetividad:

Mucho se dice de la ayuda que prestamos a los migrantes, pero lo cierto es que ellos también nos han ayudado en el camino. Gracias a la labor que realizamos hemos asumido una posición como humanas y como mujeres que no sabíamos ni pensábamos que pudiera hacer tanta diferencia (Las Patronas, 2015).

Al mismo tiempo y debido a su visibilidad, el colectivo de mujeres logró tejer una red de relaciones solidarias y se incorporaron al trabajo más profesional que realizaban coaliciones como la Dimensión Pastoral de la Movilidad Humana del Episcopado Mexicano encabezado por la hermana Leticia Gutiérrez Valderrama, religiosa de la congregación Scalabriniana. Este grupo de trabajo montó una plataforma nacional de albergues para migrantes y organizaciones defensoras de Derechos Humanos, vinculada ideológicamente con la Teología de la Liberación, que interpreta al evangelio como la "opción por los pobres", entendiendo que la pobreza proviene de la injusticia social y no del designio divino (Vigil, 2004). En este contexto, la práctica de las Patronas encontró un espacio de reflexión y transformación de su subjetividad política, pasando a auto-concebirse como defensoras de los Derechos Humanos.

El registro de estos procesos puede seguirse a través de los testimonios de su propio blog, en las entrevistas y también en los registros vídeo documentales, particularmente si se establecen comparativas entre los discursos a lo largo del tiempo, donde es posible observar el desplazamiento hasta un lugar de autoridad y conocimiento que trasciende la acción reactiva y espontánea que caracteriza la subalternidad:

Nosotras no sólo nos dedicamos a la atención de migrantes, cada una de las mujeres que trabajamos en el comedor somos también madres y campesinas y ello nos permite hablar de la situación tan precaria en que vivimos la mayoría de las y los mexicanos y es que parece no hay congruencia entre el sueldo mínimo al que acceden los trabajadores y los servicios públicos que debemos pagar... (Las Patronas, 2015). 
En este discurso dirigido ante el Congreso mexicano y el Presidente de la república, al recibir el Premio Nacional de Derechos Humanos 2013, las Patronas despliegan muchos elementos que permiten dar cuenta de que su experiencia personal ha sido transformada en herramienta política.

Un aspecto relevante en los testimonios, y particularmente de los testimonios de mujeres en resistencia, es la posibilidad de observar la manera en la que se representan a sí mismas en contraste con las características y las posiciones de subordinación que provienen de un contexto machista y patriarcal en el que las mujeres son concebidas como débiles, sumisas, apolíticas, domésticas, propiedad, objeto sexual, etc. como ha sido bien documentado por la crítica feminista. En ambos casos presentados, así como en los testimonios de las mujeres zapatistas y muchos otros de América Latina, es posible observar el reconocimiento de una subjetividad femenina empoderada por la propia experiencia de lucha, que en el caso de las Patronas se define de la siguiente manera:

Nos dijeron que éramos mujeres enfrentando problemas que estaban fuera de nuestros alcances. Y si, nuestra labor comenzó desde nuestra posición como mujeres de familias tradicionales, de costumbres que no permiten las acciones femeninas dentro del hogar y de tu pueblo, pasábamos los días cuidando, brindando amor a nuestras familias y fue justamente eso lo que nos dio el carácter para cuidar a muchas otras y otros (Las Patronas, 2015).

Respecto a los rasgos de empoderamiento que se registran en las autorrepresentaciones, no estoy estableciendo ingenuamente que el acto testimonial signifique por sí mismo una ruptura, al contrario, tenemos que observar cuidadosamente, pues allí encontraremos las contradicciones propias de la subalternidad que incorporan tanto como rechazan al discurso hegemónico. En el caso de las mujeres y la lucha en contra de la dominación patriarcal, resulta clara la tensión que Teresa de Lauretis (2007) llama "paradoja feminista"; un modo de autodefinición que necesariamente utiliza las categorías de la opresión, en tanto son aquellas que se tienen disponibles: mujer, indígena, anciana, pobre... todas cargadas de significado, e insertas en una estructura de poder que necesariamente establece una posición social determinada por el discurso dominante. En todo caso, el testimonio es una forma de visibilizar esta contradicción y esta paradoja, permitiendo la posibilidad de reflexionar sobre ellas, y favoreciendo un proceso de transformación subjetiva. Yúdice sintetiza lo anterior perfectamente en este párrafo:

Más que representación, estos textos [testimoniales] enfocan las maneras en que diversos grupos oprimidos de mujeres, campesinos, indígenas, trabajadores, domésticas, fieles, squatters, etc. Practican su identidad no sólo como resistencia a la opresión sino también como cultura afirmativa, como estética práctica (Yúdice, 2002: 227).

Esta llamada "estética práctica", es lo que en el testimonio de los subalternos va produciendo un imaginario distinto respecto a los sujetos que lo practican y replican en sus discursos, entretejiendo también la voluntad de llegar a otros desde una posición y forma no necesariamente dependiente de un 
intérprete ni necesariamente pensada para un receptor particular, como en el caso del testimonio literario cuya función original implica una estética relacionada con el consumo de un público específico.

\section{Conclusiones}

Desde mi punto de vista el género testimonial como literatura es uno de los subproductos posibles de la forma de acción política testimonial, pero no es ni el principal ni el único, y tampoco puede considerarse materia aparte del proceso histórico en el que se inserta. Las razones de mi afirmación se han desarrollado a lo largo del presente trabajo y se hacen evidentes ante la imposibilidad de definir el canon del testimonio, fijar sus límites, comprenderlo factualmente, ni estudiarlo a partir de una disciplina académica única. De cualquier manera, considero relevante enfatizar los siguientes puntos que condensan mi argumento:

- A través del registro sucesivo del testimonio y prácticas de un mismo colectivo o sujeto, surge la posibilidad de seguir un proceso de conciencia política y un correspondiente deslizamiento de la posición subalterna.

- El testimonio permite registrar un proceso de catarsis a través del cual se identifican los elementos hegemónicos incorporados, la manera como se avanza y retrocede en el desplazamiento hacia la autonomía, y aquello que facilita o imposibilita el proceso.

- Dar testimonio tiene una relevancia pedagógica en tanto ordena y reflexiona sobre las propias experiencias de resistencia a la dominación, para los propios sujetos que la experimentan y para quienes las reciben como interlocutores.

- El testimonio visibiliza la relevancia histórica propia, y fomenta la práctica del auto-registro de la experiencia.

Por otro lado, considero que los nuevos medios de registro y divulgación, tan a la mano para los propios actores sociales, facilitan la emergencia de la acción testimonial sin necesidad de intermediarios, posibilitan su diseminación masiva y producen efectos mucho más inmediatos en los receptores, que puede provocar una multiplicidad de interacciones transformadoras, una constante retroalimentación y el rápido intercambio de percepciones (proyecciones, fantasías y expectativas) entre los testimoniantes y destinatarios. Por supuesto, las relaciones que se establecen entre los testimoniantes, editores/gestores (si los hay) y destinatarios son mucho más horizontales y los roles eventualmente intercambiables (por ejemplo como sucede con las comparticiones zapatistas).

Comprender al testimonio como acción política y no solamente como género literario permite superar la producción del testimonio como producto de consumo para las élites, pero se requiere 
también de una lectura distinta y un compromiso social por parte de los académicos y críticos, cuya labor de observación sigue siendo indispensable.

En primer lugar, habría que interrogarse por el testimonio en tanto proceso y no como imagen estática: Rigoberta Menchú sin duda no es la misma Rigoberta hoy, que aquella que se dirigió a Elizabeth Burgos en 1993 ¿Cómo ha cambiado su conciencia? ¿Necesitaría en 2016 una mediadora para contárnoslo? ¿Su proceso de subjetividad avanzó hacia la autonomía, o hacia un consenso mayor con la hegemonía? En segundo lugar, el trabajo académico tendría que servir para informar las prácticas de los sujetos sobre los que se teoriza, se hace necesaria una labor de encuentro e intercambio entre sujetos testimoniantes y críticos.

En tercer lugar habría que reconocer siempre el propio lugar de enunciación y hacer explícita la propia posición política y afectos. Al observar y publicar es inevitable ejercer una forma de poder sobre los otros; fantasías, filias y fobias se proyectan en el trabajo académico y con estos filtros los sujetos se dan a conocer y exponen. Incluso las disciplinas con mejores candados para garantizar la neutralidad, no pueden pretender que la conciencia académica es transparente y mediata (mientras que la de los subalternos es turbia y contradictoria).

Por último, me gustaría concluir que encuentro que el núcleo de la relación entre testimonio y subalternidad, no es la incorporación de la "historia desde abajo" a la historia hegemónica, sino la construcción de una historia para sí, que es por un lado registro del propio proceso de subjetividad, y por otro una herramienta que tiene distintos fines políticos según los sujetos particulares y los procesos sociales en los que se inserte. 
Mariana Espeleta. Testimonio y subalternidad hoy...

\section{Bibliografía:}

Argüello, Lizette (2009). La Patrona. México: Sacbé producciones.

Beverley, John. "El testimonio en la encrucijada”. Revista Iberoamericana 164-165 (1993): 485-495. DOI: http://dx.doi.org/10.5195/reviberoamer.1993.5169.

Burgos Debray, Elizabeth (1983). Me llamo Rigoberta Menchú y así me nació la conciencia. La Habana: Casa de las Américas.

Cordero, José Antonio y Sánchez Orozco, Alejandra (2006). Bajo Juárez, la ciudad devorando a sus hijas. México: Instituto Mexicano de Cinematografía (IMCINE).

Corte Interamericana de Derechos Humanos. “Sentencia Caso González y Otras (Campo Algodonero) Vs. México. Sentencia de 16 de noviembre de 2009 ". Página oficial Corte Interamericana (2009).

Chakrabarty, Dipesh (2010). “Una pequeña historia de los Estudios subalternos” Sandoval, Pablo (comp.) Repensando la subalternidad. Miradas críticas desde / sobre América Latina. Popayán: Envión Editores: 25-52.

De Lauretis, Teresa (2007). Figures of Resistance: Essays in Feminist Theory. Chicago: University of Illinois Press.

Dirdamal, Tin y Argüello, Lizette (2005). De Nadie. México: Producciones Tranvía.

Ejército Zapatista de Liberación Nacional. “Comisión intergaláctica del EZLN”. Youtube (2006).

Espeleta Olivera, Mariana (2015). Subalternidades femeninas: la autorrepresentación como resistencia (Doctorado). Barcelona: Universidad de Barcelona.

Frente Zapatista de Liberación Nacional. "Participación de las mujeres en el gobierno autónomo" (2013).

Gramsci, Antonio (1981). Cuadernos de la cárcel, tomo 2. Gerratana, Valentino (ed.). Ciudad de México: ERA.

Gramsci, Antonio(1986). Cuadernos de la cárcel, tomo 4. Gerratana, Valentino (ed.). Ciudad de México: ERA.

Guha, Ranahit (1996). "The Small Voice of History” Shahid, Amin y Chakrabarty, Dipesh (eds.) Subaltern Studies IX. Writings on South Asian History and Society. Delhi: Oxford University Press: 1-12.

González Rodríguez, Sergio (2002). Huesos en el desierto. Barcelona: Anagrama. 
Las Patronas. “Discurso Premio Nacional de Derechos Humanos 2013”. Blog de las Patronas (2013).

Las Patronas. "20 años de Las Patronas”. Blog de las Patronas (2015).

Monarrez Fragoso, Julia (2009). Trama de una injusticia. Feminicidio sexual sistémico en Ciudad Juárez. Ciudad de México: Colegio de la Frontera Norte y Miguel Ángel Porrúa.

Ortiz, Maricela. “Solidaridad en Alemania contra feminicidio en México”. CIMAC noticias (2005).

Portillo, Lourdes (2001). Señorita Extraviada. México: Xochitl Productions.

Ravelo Blancas, Patricia. "Entre las protestas callejeras y las acciones internacionales. Diez años de activismo por la justicia social en Ciudad Juárez”. El Cotidiano 125 (2004): 21-32.

Ravelo Blancas, Patricia (2010). "We Never Thought It Would Happen to Us: Approaches to the Study of Subjectivities of the Mothers of the Murdered Women of Ciudad Juarez". DomínguezRuvalcaba, Héctor y Corona, Ignacio (eds.) Gender Violence at the US Mexico Border. Media Representation and Public Response. Arizona: University of Arizona Press: 35-57.

Reyes, Alejandro. “¿Para qué sirven las comparticiones?”. Radio Zapatista (2014).

Segato, Rita Laura (2006). La escritura en el cuerpo de las mujeres asesinadas en Ciudad Juárez: territorio, soberanía y crímenes de segundo estado. México: Universidad del Claustro de Sor Juana.

Sklodowska Elzbieta (1992). Testimonio hispanoamericano: historia, teoría, poética. Nueva York: Peter Lang.

Spivak, Gayatri. “¿Puede hablar el subalterno?”. Revista Colombiana de Antropología 39 (2003): 297-364.

Viezzer Moema (1977), Si me permiten hablar... testimonio de Domitila, una mujer de las minas de Bolivia. Buenos Aires: S. XXI.

Vigil, José Maria. "La opción por los pobres es opción por la justicia, y no es preferencial. Para un reencuadramiento teológico-sistemático de la opción por los pobres”. Theologica Xaveriana 149 (2004): 141-156.

Washington Valdés, Diana (2005). Cosecha de mujeres: safari en el desierto mexicano. Ciudad de México: Océano.

Yúdice, George (2002). “Testimonio y concientización”. Beverley John y Achúgar Hugo (eds.) La Voz del Otro: Testimonio, Subalternidad y Verdad Narrativa. Guatemala: Universidad Rafael Landívar: 221-242. 